\title{
Venación foliar de tres especies de Cedrela (Meliaceae) de los andes del Perú
}

\section{Leaf venation of three Cedrela species (Meliaceae) from the Andes of Peru}

\author{
Akira A. Wong Sato ${ }^{1,2, \star}$ y Carlos Reynel ${ }^{1}$
}

Recibido: 10 enero 2021 | Aceptado: 19 setiembre 2021 | Publicado en línea: 29 diciembre 2021 Citación: Wong Sato, AA; Reynel, C. 2021. Venación foliar de tres especies de Cedrela (Meliaceae) de los andes del Perú. Revista Forestal del Perú 36(2): 227-246. DOI: http://dx.doi.org/10.21704/rfp. v36i2.1800

\begin{abstract}
Resumen
Información sobre la venación foliar del género Cedrela, y de la familia Meliaceae en general, es escasa. En este estudio usamos la técnica de diafanización para facilitar la caracterización de la venación foliar de tres especies de Cedrela: C. angustifolia, C. montana y C. nebulosa. Además, usamos análisis de correspondencia múltiple para determinar si existe alguna relación entre las especies estudiadas y ciertas características de sus venaciones. Las tres especies estudiadas presentan características similares de venación laminar, venaciones inferiores y superiores, areolas y vénulas. Asimismo, los análisis de correspondencia múltiple sugieren que la venación foliar es muy similar entre las tres especies. Sin embargo, C. nebulosa puede ser diferenciada de las otras dos especies estudiadas por su angosta vena primaria en relación con el ancho de la lámina.
\end{abstract}

Palabras clave: Cedrela, Meliaceae, venación foliar, diafanización

\begin{abstract}
Information on the foliar venation of the genus Cedrela, and in general of the Meliaceae family, is scarce. In this study, we used the diaphanization technique to facilitate the characterization of foliar venation of three Cedrela species: C. angustifolia, C. montana and C. nebulosa. Furthermore, we used a various multiple correspondence analysis to determine if there is any relationship between the studied species and specific characteristics of their venation patterns. The three studied species showed similar characteristics of laminar venation, lower and upper veins, areolae, and venules. Similarly, the multiple correspondence showed that the foliar venation patterns of the three studied species is similar. However, C. nebulosa can be differentiated from the other two studied species by its narrow primary vein in relation to the width of the lamina.
\end{abstract}

Key words: Cedrela, Meliaceae, foliar venation, diaphanization

\footnotetext{
${ }^{1}$ Departamento Académico de Manejo Forestal, Universidad Nacional Agraria la Molina (UNALM), Lima, Perú.

${ }^{2}$ División de Ecología Vegetal - CORBIDI, Lima, Perú.

*Autor de Correspondencia: ws.akira@corbidi.org
} 


\section{Introducción}

El género Cedrela L. (Meliaceae) es nativo del Neotrópico. Se encuentra desde México hasta Argentina, ampliamente distribuido en bosques caducifolios tropicales (Muellner et al. 2010). Este género se encuentra muy emparentado a Toona (Endl.) M.Roem. único género con el que forma la tribu Cedreleae (Muellner et al. 2003); a pesar de esto, ambos géneros no comparten la misma distribución (Hua y Edmonds 2008).

Varias especies de Cedrela poseen elevado valor comercial por la alta calidad de sus maderas, y son actualmente sobreexplotadas. Dentro de la Lista Roja de la UICN, podemos encontrar especies clasificadas en Peligro crítico: Cedrela discolor S. F. Blake (Fuentes et al. 2019a) y Cedrela dugesii S. Watson (Samain et al. 2019); en Peligro: Cedrela oaxacensis C. DC. \& Rose y Cedrela angustifolia Moc. \& Sesse ex DC. (Llamozas 1998, Fuentes et al. 2019b), como Vulnerable: Cedrela odorata L. y Cedrela fissilis Vell (Mark y Rivers 2017, Barstow 2018); y finalmente en Preocupación Menor Cedrela tonduzii C. DC. y Cedrela salvadorensis Standl. (BGCI e IUCN 2019, Fuentes et al. 2019c). Adicionalmente, todas las poblaciones del Neotrópico de Cedrela spp. se encuentran en el apéndice II de CITES (CITES 2021).

La identificación de especies del género Cedrela es indispensable para el planeamiento, desarrollo y ejecución de actividades económicas; especialmente en regiones donde la diversidad de especies es muy alta, como el Perú, y diferentes especies pueden compartir características morfológicas vegetativas, aun siendo miembros de diferentes taxones.

La familia Meliaceae y el género Cedrela cuentan con caracteres diagnóstico que ayudan a su identificación. Los caracteres diagnósticos de la familia Meliaceae son: hojas alternas y compuestas, pinnadas o bipinnadas; flores actinomorfas, con estambres parcial o completamente fusionados en un tubo $y$ frecuentemente con un disco nectarífero intraestaminal; frutos cápsulas, bayas o drupáceos; semillas secas y aladas o carnosas y sin alas. Y los caracteres diagnósticos del género Cedrela son: corteza externa agrietada; hojas paripinnadas, raramente imparipinnadas; foliolos falcados con bases asimétricas; fruto cápsula ovoide 3-5-valvado con semillas aladas. Adicionalmente, Gentry (1996) y Reynel et al. (2003) mencionan que la corteza interna de Cedrela posee un olor similar al ajo.

La venación foliar ha demostrado su utilidad taxonómica para varios ordenes de plantas con flores como Alismatales (Fonsêca et al. 2007), Asterales (Aworinde et al. 2013), Gentiales (Pacheco-Trejo et al. 2009) y Malpighiales (Cervantes et al. 2009), entre otros; e incluso en helechos (Tejero-Díez et al. 2010). Para el orden Sapindales, los estudios enfocados en la venación foliar son escasos, pero se han realizado para las familias Sapindaceae (Buijsen 1995, Adeyemi et al. 2013, Cao et al. 2014), Rutaceae (Muntoreanu et al. 2011), Simaroubaceae (Cronquist 1944, Wendt y Lott 1985), Meliaceae (Sarma et al. 1992, Tadavi y Bhadane 2013) y Anacardiaceae (Andrés-Hernández y Terrazas 2009); demostrando la importancia de la venación foliar para estas familias, con la excepción de Simaroubaceae.

Particularmente para Meliaceae, Sarma et al. (1992), y Tadavi y Bhadane (2013) realizaron estudios donde se comparó la venación foliar de varias especies de Meliaceae, y determinaron que la venación de la lámina, la venación marginal y las areolas son características de importancia taxonómica, Tadavi y Bhadane (2013) también consideraron que lo son la vena primaria y las vénulas.

La venación foliar del género Cedrela ha sido escasamente descrita. Las descripciones y comparaciones de Sarma et al. (1992), y Tadavi y Bhadane (2013) no consideran especies de este género; Sarma et al. (1992) originalmente consideró a Cedrela serrata Royle y Cedrela toona Roxb., pero actualmente son consideradas sinónimos de Toona sinensis (Juss.) M. Roem y Toona ciliata M.Roem, respectivamente. Pennington y Muellner (2010) describieron una venación laminar eucamptódroma para la totalidad de especies del género, con 
excepción de $C$. montana, que presenta un patrón de venación laminar eucamptódroma o broquidódroma. Estas descripciones de $\mathrm{Ce}$ drela coinciden con las de Pennington (2006) para C. fissilis y C. odorata, especies de Cedrela distribuidas en la Reserva Ducke (Brasil), las cuales junto con C. angustifolia son las tres especies de Cedrela distribuidas en territorio brasileño (Pennington 1981). Reynel et al. (2017) incluyen el número de pares de venas secundarias como la única característica de venación foliar en sus descripciones de Cedrela spp. del Perú, característica que usa para la diferenciación de estas especies. Con excepción del ejemplo anterior, no se han determinado otras características de la venación foliar de importancia taxonómica para Cedrela.

El objetivo de este estudio es contribuir a la identificación de Cedrela (Meliaceae) en Perú, determinando patrones de variación en la nervación foliar que pueden tener un valor taxonómico para la identificación grupal de este taxón. Se trata del primer estudio sobre la venación foliar de Cedrela en Perú.

\section{Materiales y Métodos}

\section{Especies estudiadas}

a) Cedrela angustifolia Sessé \& Moc. ex DC. (sinónimos: Cedrela boliviana Rusby, Cedrela herrerae Harms, Cedrela lilloi C. DC., Cedrela steinbachii Harms, Pterosiphon multivenius Turcz., Surenus angustifolia (Sessé \& Moc. ex DC.) Kuntze)

Cedrela angustifolia se encuentra distribuida en Ecuador, Perú, Bolivia y Argentina, en bosques húmedos montanos y de neblina, casi siempre entre 1800-3500 msnm (Pennington y Muellner 2010, Reynel et al. 2017). En Perú se encuentra distribuido entre 1100-1200 msnm, en los departamentos de Amazonas, Ancash, Apurímac, Cajamarca, Pasco, Cuzco, Junín y Piura (Reynel et al. 2017). Posee una amplia distribución, abarcando toda la sierra peruana, pero tiene una densidad poblacional baja debido a la tala con fines maderables, desde épocas coloniales, y por la segmentación de los bosques con fines agrícolas (Reynel et al. 2017).

Foliolos de forma lanceolada, con ancho foliar de 2-3.5 cm (Reynel et al. 2017). Venación laminar eucamptódroma, (9-)11-17 pares de venas secundarias, ascendientes, rectas y paralelas. Venaciones superiores reticuladas o areoladas (Pennington y Muellner 2010). Reynel et al. (2017) señala que tiene 15-22 pares de venas secundarias.

\section{b) Cedrela montana Moritz ex Turcz}

Cedrela montana se encuentra distribuida en Colombia, Venezuela, Ecuador y Perú, en bosques húmedos montanos y de neblina, entre 1300-3000 msnm (Pennington y Muellner 2010, Reynel et al. 2017). Esta especie se encuentra distribuido entre 1300-3000 msnm, en los departamentos de Amazonas, Pasco y San Martín, y tiene poblaciones reducidas o extremadamente reducidas (Reynel et al. 2017).

Foliolos de forma lanceolada-oblonga, con ancho foliar de 3-6 cm (Reynel et al. 2017). Venación laminar eucamptódroma o broquidódroma, 15-23 pares de venas secundarias frecuentemente extendiéndose o ligeramente ascendente, rectas o ligeramente arqueada, paralelas. Venaciones superiores reticuladas o areoladas (Pennington y Muellner 2010). Reynel et al. (2017) señala que tiene 12-16 pares de venas secundarias.

\section{c) Cedrela nebulosa T. D. Penn. \& Daza}

Cedrela nebulosa se encuentra distribuida en Colombia, Ecuador y Perú, en bosques húmedos montanos y de neblina, principalmente entre 1100-2400 msnm; asimismo es común en bosques perturbados y secundarios (Pennington y Muellner 2010, Reynel et al. 2017). En Perú se encuentra distribuido entre 1100-2400 msnm, en los departamentos de Amazonas, Cajamarca, Pasco, Junín, San Martín y Ucayali, y tiene poblaciones reducidas o extremadamente reducidas (Reynel et al. 2017).

Foliolos de forma lanceolada-oblonga/elíptica, con un ancho foliar de 5-7 cm (Reynel et al. 2017). Venación laminar eucamptódroma, 11-16 pares de venas secundarias, superficial- 


\begin{tabular}{|c|c|c|c|c|c|c|}
\hline \multirow[b]{2}{*}{ Especie } & \multirow{2}{*}{$\begin{array}{c}\text { Código de } \\
\text { la muestra } \\
\text { obtenida }\end{array}$} & \multicolumn{5}{|c|}{ Datos de especímenes usados } \\
\hline & & Lugar de colecta & $\begin{array}{l}\text { Coordenadas } \\
(\mathrm{S}, \mathrm{O})^{1}\end{array}$ & $\begin{array}{c}\text { Altura } \\
\text { (msnm) }\end{array}$ & Código de colecta & $\begin{array}{l}\text { Fecha de } \\
\text { colección }\end{array}$ \\
\hline \multirow{4}{*}{ 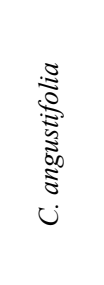 } & A1 & $\begin{array}{c}\text { Junín - San } \\
\text { Ramón }\end{array}$ & - & 2000 & $\begin{array}{l}\text { T. D. Pennington } \\
\text { et al., } 17723\end{array}$ & $\begin{array}{c}26-30 \text { nov } \\
2004\end{array}$ \\
\hline & $\mathrm{A} 2$ & $\begin{array}{c}\text { Cuzco - } \\
\text { Challabamba }\end{array}$ & $13^{\circ} 02^{\prime}, 71^{\circ} 48^{\prime}$ & 2490 & C. Flores et al. 429 & 23 mar 2002 \\
\hline & A3 & Pasco - Oxapampa & - & 2005 & $\begin{array}{c}\text { A. Daza et al. } \\
4272\end{array}$ & $\begin{array}{c}30 \text { ago }-3 \text { set } \\
2005\end{array}$ \\
\hline & A4 & Cuzco - Oropesa & $13^{\circ} 35^{\prime}, 71^{\circ} 47^{\prime}$ & 3100 & C. Flores N. 425 & $9 \operatorname{mar} 2002$ \\
\hline \multirow{4}{*}{ 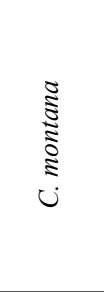 } & M1 & Junín - Satipo & - & $\begin{array}{c}1200- \\
1300\end{array}$ & I. Larco Roca s/n & 27 ago 1998 \\
\hline & M2 & Junín - Rio Tambo & - & 1358 & $\begin{array}{l}\text { A. Daza y M. D. } \\
\text { Silvia } 5724\end{array}$ & 3 nov 2013 \\
\hline & M3 & Pasco - Oxapampa & - & 2300 & E. Vasquez A. 110 & 9 ago 1967 \\
\hline & M4 & $\begin{array}{c}\text { Amazonas - San } \\
\text { Carlos }\end{array}$ & $5^{\circ} 53^{\prime}, 77^{\circ} 56^{\prime}$ & 2300 & $\begin{array}{l}\text { T. D. Pennington y } \\
\text { A. Daza } 18709\end{array}$ & 24 nov 2007 \\
\hline \multirow{4}{*}{ 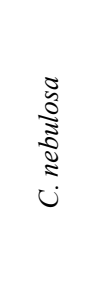 } & N1 & $\begin{array}{c}\text { Pasco - } \\
\text { Huancabamba }\end{array}$ & $10^{\circ} 26^{\prime}, 75^{\circ} 30^{\prime}$ & 1700 & $\begin{array}{l}\text { T. D. Pennington y } \\
\text { A. Daza } 16441\end{array}$ & 19 nov 1998 \\
\hline & $\mathrm{N} 2$ & $\begin{array}{l}\text { Amazonas - } \\
\text { Florida }\end{array}$ & $5^{\circ} 42^{\prime}, 77^{\circ} 54^{\prime}$ & 1920 & $\begin{array}{l}\text { T. D. Pennington y } \\
\text { A. Daza } 16804\end{array}$ & 26 nov 1999 \\
\hline & N3 & Pasco - Oxapampa & - & 1850 & A. Daza 4030 & 30 dic 2004 \\
\hline & N4 & $\begin{array}{c}\text { Amazonas - Pedro } \\
\text { Ruíz Gallo }\end{array}$ & $5^{\circ} 45^{\prime}, 77^{\circ} 40^{\prime}$ & 1700 & $\begin{array}{l}\text { T. D. Pennington } \\
\text { et al. } 17645\end{array}$ & 4 dic 2003 \\
\hline
\end{tabular}

Cuadro 1. Especímenes usados para la colección de muestras y detalles de su colección. 1 Algunas colecciones no presentaban datos de coordenadas. En el caso de M2, los datos de las coordenadas son incorrectos y fueron obviados.

mente ascendientes, rectas o algo ligeramente arqueadas, paralelas. Venaciones superiores ambiguas, oblicuas a reticuladas (Pennington y Muellner 2010, Reynel et al. 2017).

\section{Selección de material foliar}

La revisión taxonómica estuvo basada en especímenes de colecciones del Herbario Forestal MOL. Por cada especie estudiada se eligieron cuatro especímenes de las colecciones del herbario (Cuadro 1), número que fue limitado por la calidad de especímenes con duplicados. De cada espécimen elegido se seleccionó un foliolo intermedio de las hojas maduras. Estos foliolos fueron tratados como muestras.

\section{Diafanización}

El proceso de Diafanización usado en este estudio se basó en el desarrollado por Pariente (2018) para muestras secas. Este proceso se realizó en el Laboratorio de Pulpa y Papel y en el Laboratorio de Dendrología de la Facultad de Ciencias Forestales (FCF) - Universidad Nacional Agraria la Molina (UNALM).

\section{Medición y descripción de caracteres de la venación foliar}

Para facilitar las medidas de los niveles de venación inferior (primarias, secundarias y terciarias) y venas intersecundarias, las muestras diafanizadas fueron digitalizadas con un 
escáner Epson L495 a 1200 pp. Así mismo, las muestras fueron observadas bajo un estereoscopio LW Scientific Achiever.

En el caso de niveles de venación superior, la medida de estos elementos fue asistida con un microscopio Leica DM750 y un módulo cámara digital Leica ICC50 W del Laboratorio de Anatomía de la Madera de la FCF - UNALM, con los cuales se tomaron tres fotomicrografías $(40 \mathrm{x})$ al azar de las partes centrales de las láminas foliares de las muestras, conforme a lo recomendado por Ash et al. (1999), ya que venaciones de nivel superior, areolas y vénulas de áreas basales y apicales son variables a nivel interespecífico. Para las areolas y vénulas, se eligió una de las tres fotomicrografías anteriores al azar, por consiguiente, solo se usaron datos de las partes centrales de las láminas foliares. Se usó el software Fiji (Schindelin et al. 2012) para la medición de diversas características de las venas y areolas, de las digitalizaciones basadas en los escaneos y fotomicrografías (40 x). Finalmente, para la descripción de la venación foliar nos basamos en las clasificaciones de caracteres de venación foliar de Hickey (1973) y Ash et al. (1999).

\section{Análisis estadísticos}

Se usaron análisis de correspondencia múltiple (MCA) para caracterizar las especies estudiadas por sus venas secundarias, venas inter-secundarias, areolas y vénulas a fin de determinar su utilidad en la diferenciación de estas especies. Para este análisis se usó el software R (R Core Team 2019), con los paquetes 'FactoMineR' (Lê et al. 2008) y 'factoextra' (Kassambara y Mundt 2017).

Para las venas secundarias se tomó en cuenta el tipo de ángulo en relación con la vena primaria. Para las venas inter-secundarias, adicionalmente al tipo de ángulo, también se tomó en cuenta el tipo de vena (simple o compuesto). Se usaron los datos del total de las venas, tanto secundarias como inter-secundarias, de todo el limbo de las cuatro muestras de cada especie estudiada.

En el caso de las areolas, se usaron las clasificaciones de sus tamaños y formas (número de lados) y vénulación (presencia o ausencia de vénulas). Y en el caso de las vénulas, se usaron los datos de sus tipos. Para los datos de areolas $\mathrm{y}$ vénulas se usaron una de las tres fotomicrografías de cada muestra.

En caso de que alguna característica pueda ser potencialmente usada para la diferenciación de las especies estudiadas, esta se analizó mediante las pruebas de ANOVA y Tukey con el software R (R Core Team 2019).

\section{Depósito de muestras}

Los foliolos diafanizados de C. angustifolia (muestras A1, A2, A4 y A4), C. montana (muestras M1, M2, M4 y M4) y C. nebulosa (muestras N1, N2, N4 y N4) fueron depositadas en el herbario forestal MOL.

\section{Resultados}

\section{Descripción de la venación foliar de las espe- cies estudiadas}

a) Cedrela angustifolia Sessé \& Moc. ex DC.

Venación de la lámina pinnada y eucamptódroma (Figura 1). Vena primaria de ancho moderado (1.25-2\%) a fuerte $(2-4 \%)$ relativo a la lámina foliar, leve a claramente curvado, perceptiblemente en un arco continuo (Figura 1). Venas secundarias de ancho mediano relativo a la vena primaria, inter-espaciadas uniforme o semi-uniformemente, aumentando hacia la base y ápice, o únicamente a la base; ángulo de divergencia en el ápice es agudo-moderado $\left(45-65^{\circ}\right)$ y agudo-ancho $\left(65-80^{\circ}\right)$, en el limbo medio agudo-moderado y agudo-ancho, $\mathrm{y}$ en la base agudo-moderado, agudo-ancho y ocasionalmente recto $\left(80-100^{\circ}\right)$; recorrido en el ápice recto y abruptamente curvo, en el limbo medio recurvas, abrupta- y uniformemente curvo, y en la base recurvo, abrupta- y uniformemente curvo (Figura 1). Venas inter-secundarias raras $(0-25 \%)$ a poco frecuentes (25-50\%), simples y compuestas; ángulo de divergencia predominante en relación con la parte apical de la vena primaria recto a agudo-ancho (Figura 1). Venas terciarias con patrón mixto alterna/opuesta-percurrente (simples o ramificadas), curso bifurcado y sinuoso; ángu- 
Venación foliar de tres especies de Cedrela (Meliaceae)

A

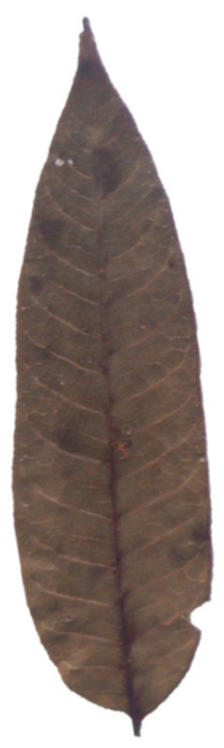

$\mathrm{C}$

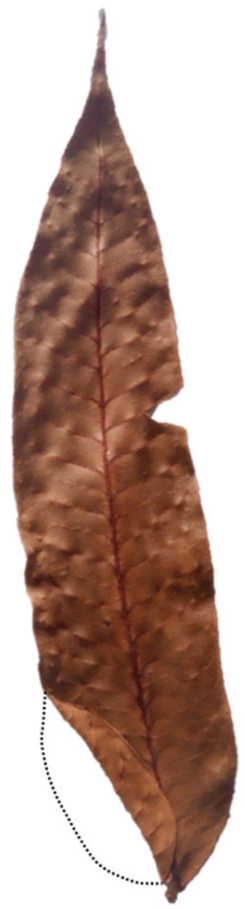

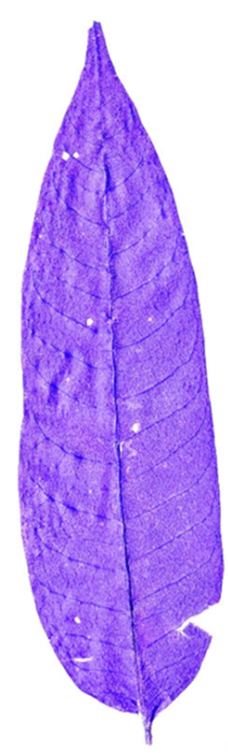

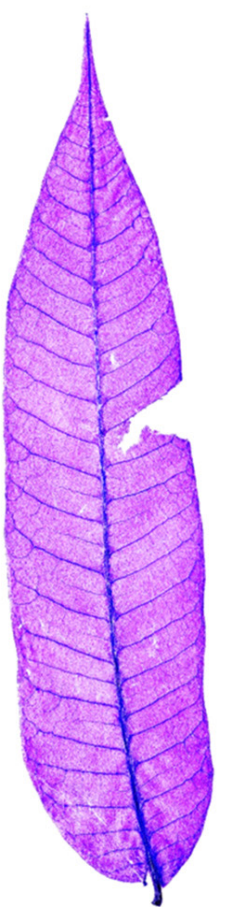

B
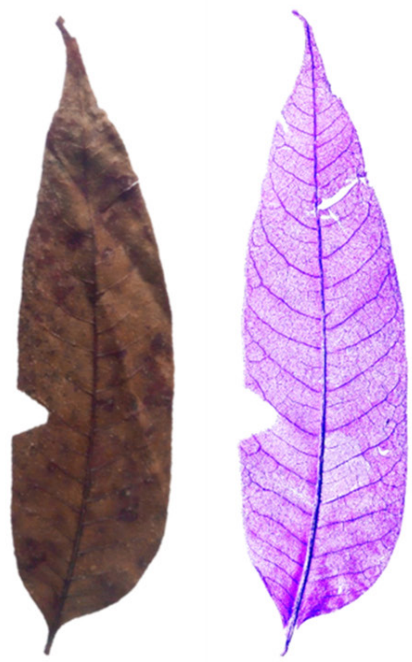

D

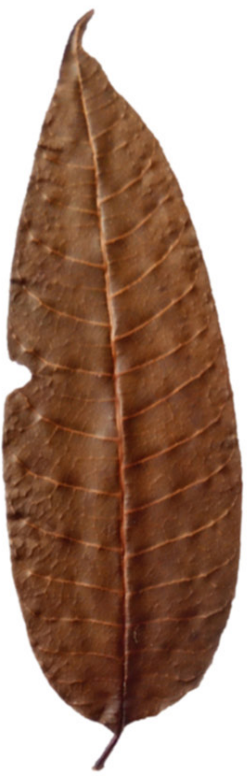

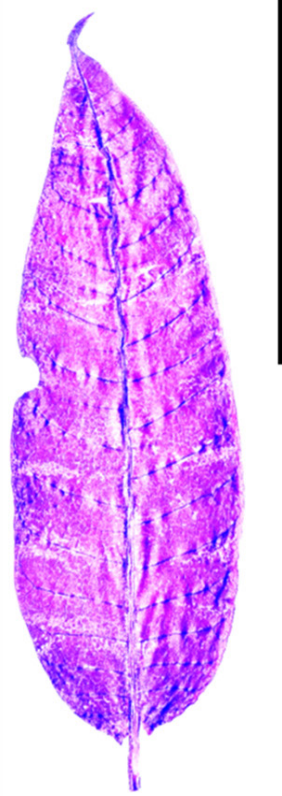

Figura 1. Foliolos de C. angustifolia antes y después del proceso de diafanización. Izquierda y derecha, foliolo antes y después del proceso de diafanización, respectivamente. (A) muestra 'A1'; (B) muestra 'A2'; (C) muestra A3'; (D) muestra 'A4'. Escala $=10 \mathrm{~cm}$. 
A

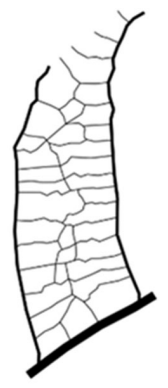

C

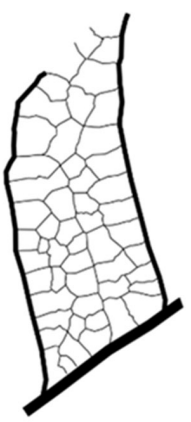

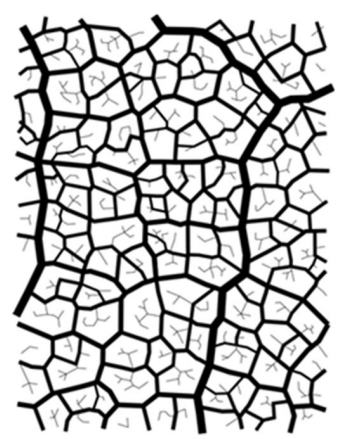

B
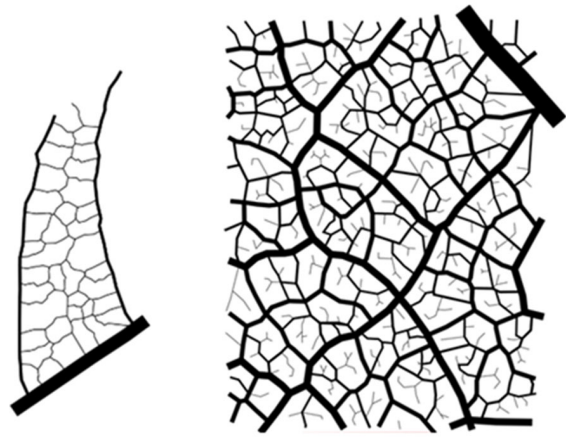

D

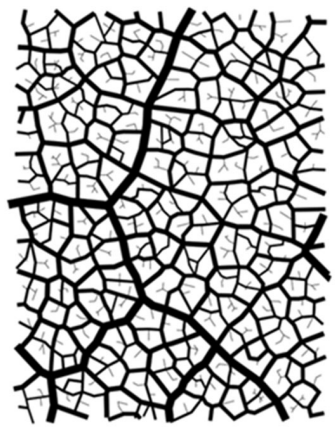

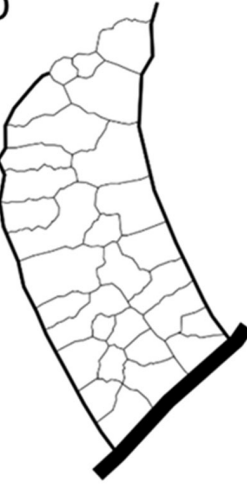

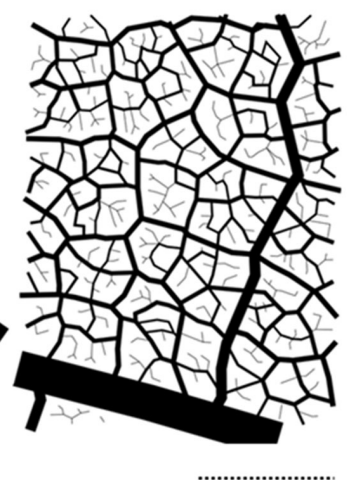

Figura 2. Detalles de venaciones terciarias, areolas y vénulas del limbo medio de foliolos de C. angustifolia. Izquierda: las líneas de mayor a menor grosos representan a la vena primaria, secundarias y terciarias, respectivamente (escala izquierda); derecha: detalles de arolas y vénulas (escala derecha). (A) muestra 'Al'; (B) muestra 'A2'; (C) muestra 'A3'; (D) muestra 'A4'. Escala izquierda $=2 \mathrm{~cm}$; escala derecha $=1000 \mu \mathrm{m}$.

lo en relación con venas secundarias recto, y en relación con la vena primaria oblicuo, decreciendo apicalmente (Figura 2). Venas cuaternarias con patrón alterna percurrente (sin ramificación) - reticuladas al azar (ángulos variados de anastomosis); ancho mediano relativo a la vena terciaria. Venas quintenarias y sextenarias reticuladas al azar. Venas septenarias dicotómicas (ramificadas libremente). Venación final marginal arqueada sin dientes (Figura 1). Areolas bien desarrolladas; pequeñas (0.01-0.1 $\left.\mathrm{mm}^{2}\right)$ a muy pequeñas $\left(<0.01 \mathrm{~mm}^{2}\right)$, escasas y medianas $\left(0.1-1 \mathrm{~mm}^{2}\right)$ raras; de cinco lados o más a cuadriláteras escasas y triangulares (Figura 2). Vénulas raramente no presentes; simples lineales a simples curvadas, bifurcadas y bifurcadas dos o más veces raras (Figura 2).

\section{b) Cedrela montana Moritz ex Turcz}

Venación de la lámina pinnada y eucamptódroma (Figura 3). Vena primaria de ancho moderado $(1.25-2 \%)$ a fuerte $(2-4 \%)$ relativo a la lámina foliar, recto o claramente curvado, perceptiblemente en un arco continuo (Figura 3). Venas secundarias de ancho mediano relativo a la vena primaria, inter-espaciadas irregular o semi-uniformemente, aumentando hacia la base y ápice, o únicamente a la base; ángulo de divergencia en el ápice agudo-moderado $\left(45-65^{\circ}\right)$ y agudo-ancho $\left(65-80^{\circ}\right)$, en el limbo medio agudo-moderado y agudo-ancho, y en la base agudo-ancho y recto $\left(80-100^{\circ}\right)$; recorrido en el ápice uniformemente curvo, en el limbo medio abrupta- y uniformemente 
A

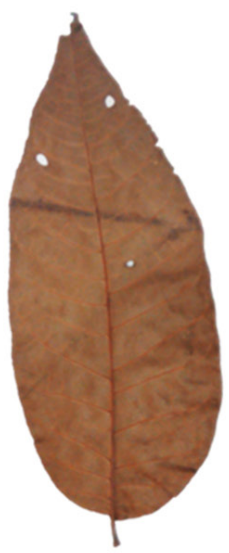

$\mathrm{C}$

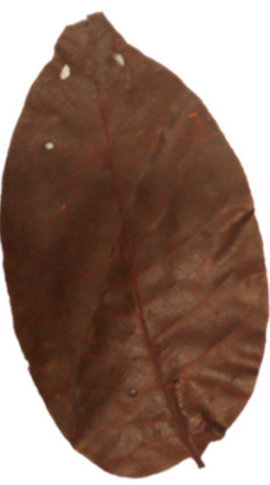

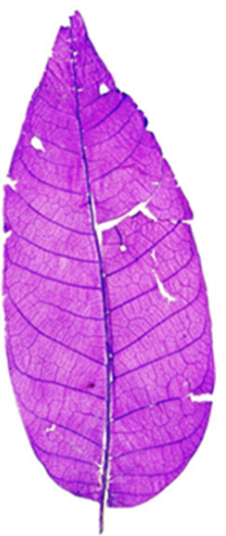

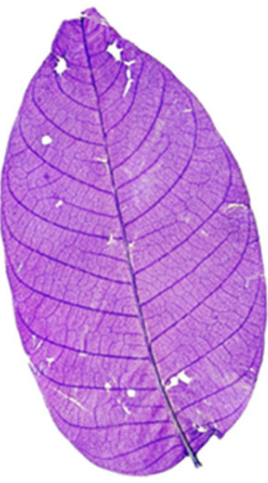

B
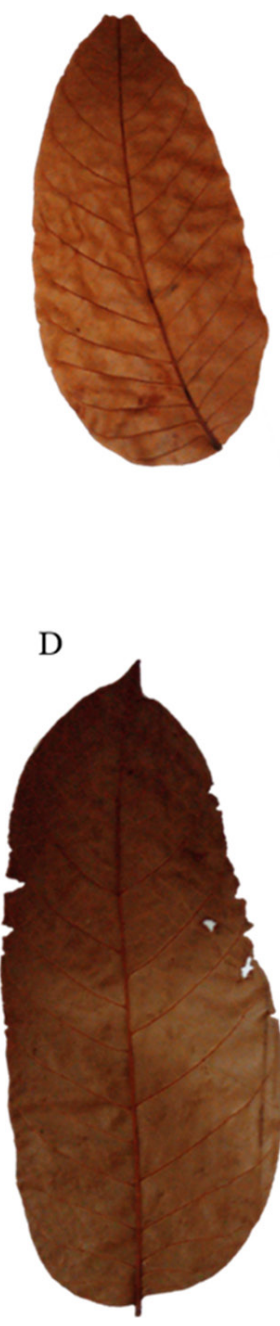
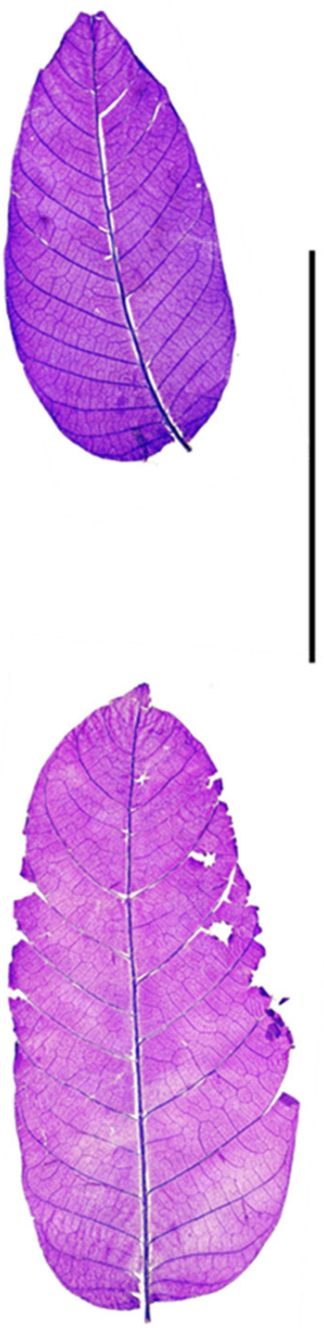

Figura 3. Foliolos de C. montana antes y después del proceso de diafanización. Izquierda y derecha, foliolo antes y después del proceso de diafanización, respectivamente. (A) muestra 'M1'; (B) muestra 'M2'; (C) muestra 'M3'; (D) muestra 'M4'. Escala $=10 \mathrm{~cm}$. 
A

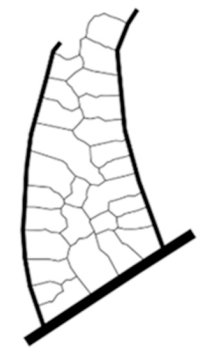

$\mathrm{C}$

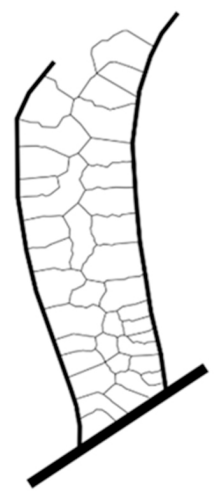

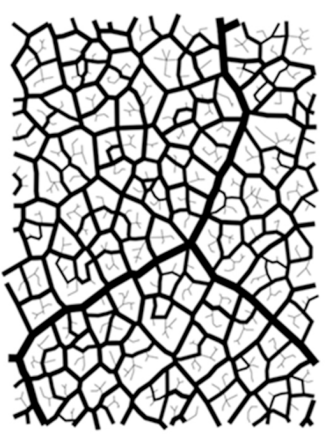

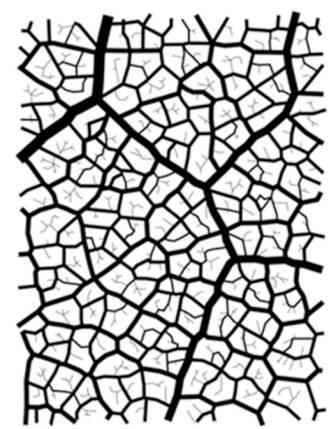

B

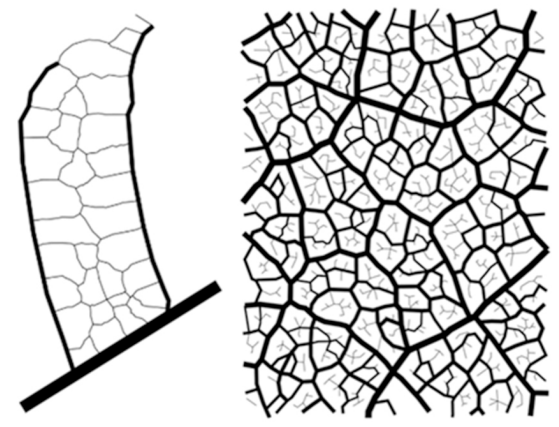

D

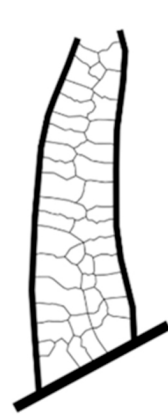

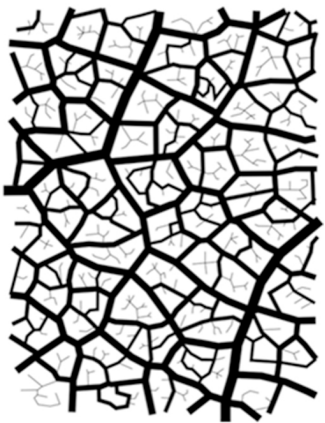

Figura 4. Detalles de venaciones terciarias, areolas y vénulas del limbo medio de foliolos de C. montana. Izquierda: las líneas de mayor a menor grosos representan a la vena primaria, secundarias y terciarias, respectivamente (escala izquierda); derecha: detalles de arolas y vénulas (escala derecha). (A) muestra 'M1'; (B) muestra 'M2'; (C) muestra 'M3'; (D) muestra 'M4'. Escala izquierda $=2 \mathrm{~cm}$; escala derecha $=1000 \mu \mathrm{m}$.

curvo, y en la base recurvo, abruptamente curvo (Figura 3). Venas inter-secundarias poco frecuentes $(25-50 \%)$ a frecuentes $(50-75 \%)$, simples y compuestas; ángulo de divergencia predominantemente en relación con la parte apical de la vena primaria agudo-ancho y en menor grado recto (Figura 3). Venas terciarias con patrón mixto alterna/opuesta-percurrente, curso bifurcado y sinuoso; ángulo en relación con venas secundarias recto, y en relación con la vena primaria oblicuo, decreciendo apicalmente (Figura 4). Venas cuaternarias con patrón alterna percurrente o reticuladas al azar; ancho mediano relativo a la vena terciaria. Venas quintenarias y sextenarias reticuladas al azar. Venas septenarias dicotómicas. Venación final marginal arqueada sin dientes (Figura 3). Areolas bien desarrolladas; pequeñas (0.01-0.1 $\left.\mathrm{mm}^{2}\right)$ a pequeñas $\left(<0.01 \mathrm{~mm}^{2}\right)$; de cinco lados o más a cuadriláteras y triangulares (Figura 4). Vénulas a veces no presentes; simples lineales, simples curvadas y bifurcadas una vez a bifurcadas dos menos comunes y bifurcadas tres o más veces raras (Figura 4).

\section{c) Cedrela nebulosa T. D. Penn. \& Daza}

Venación de la lámina pinnada y eucamptódroma (Figura 5). Vena primaria de ancho débil $(<1.25 \%)$ relativo a la lámina foliar, recto a claramente curvado, perceptiblemente en un arco continuo (Figura 5). Venas secundarias de ancho mediano relativo a la 
A

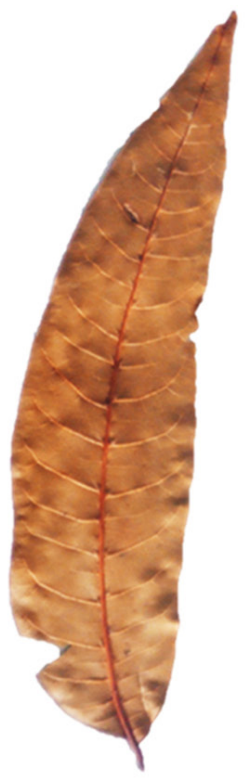

C

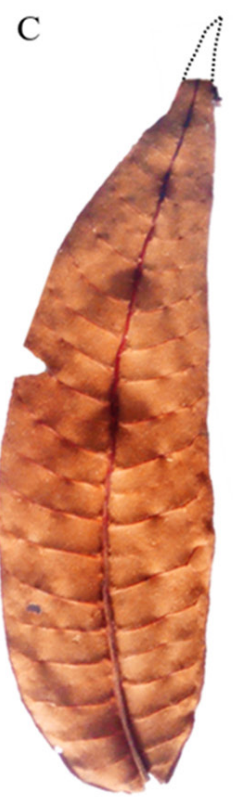

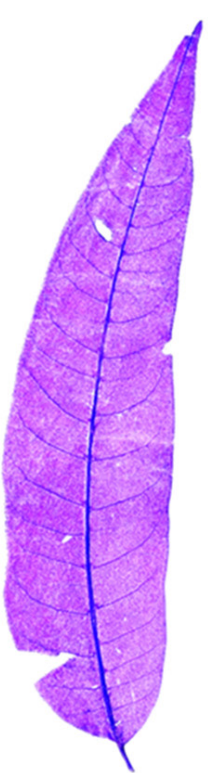

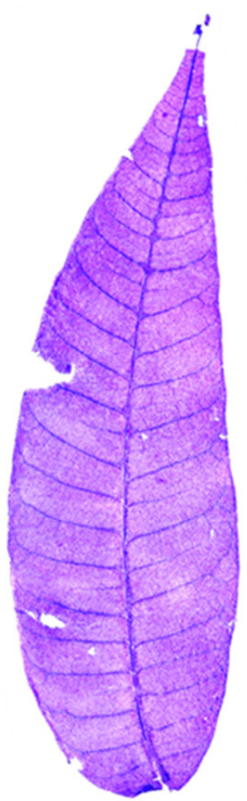

B
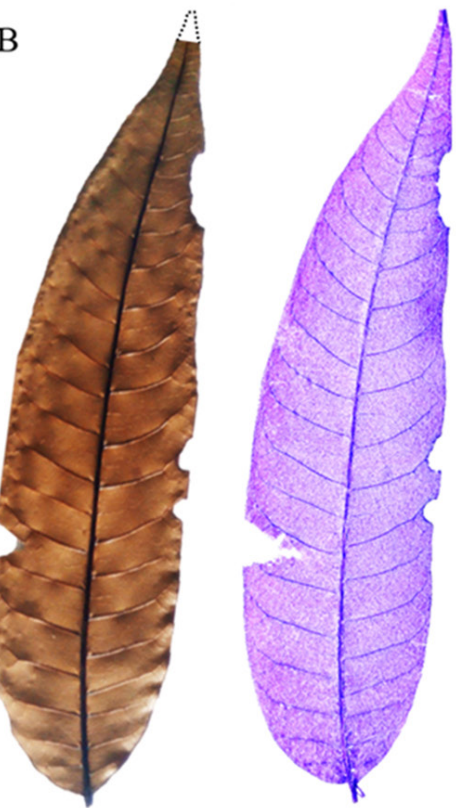

$\mathrm{D}$
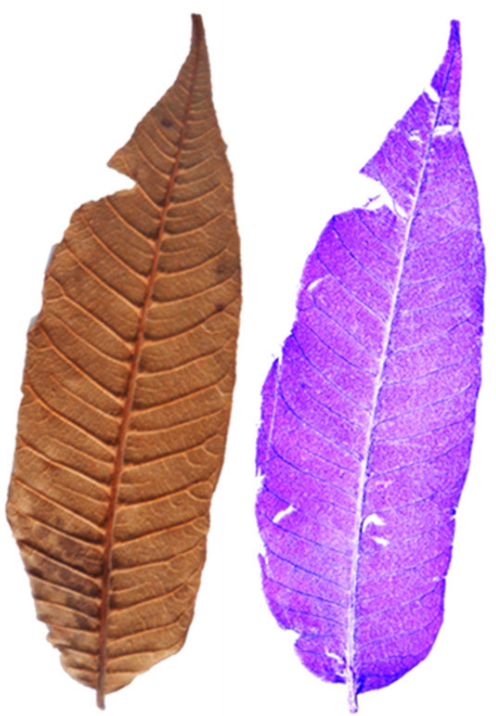

$\mid$

Figura 5. Foliolos de C. nebulosa antes y después del proceso de diafanización. Izquierda y derecha, foliolo antes y después del proceso de diafanización, respectivamente. (A) muestra 'N1'; (B) muestra 'N2'; (C) muestra 'N3'; (D) muestra 'N4'. Escala $=10 \mathrm{~cm}$. 
A

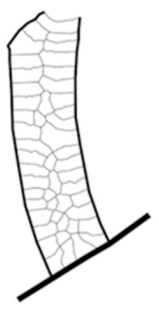

C

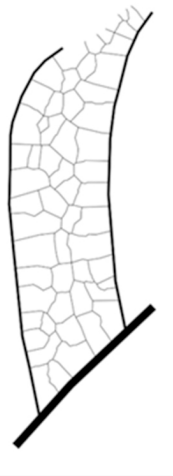

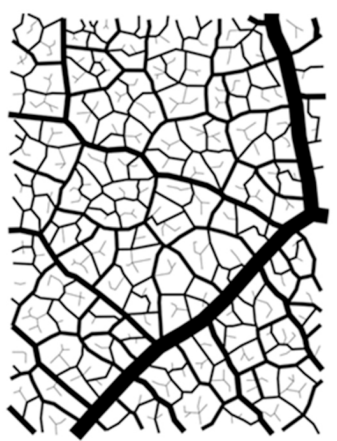

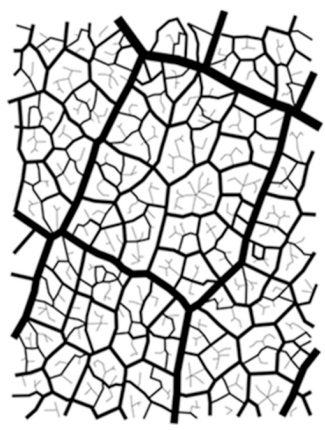

B
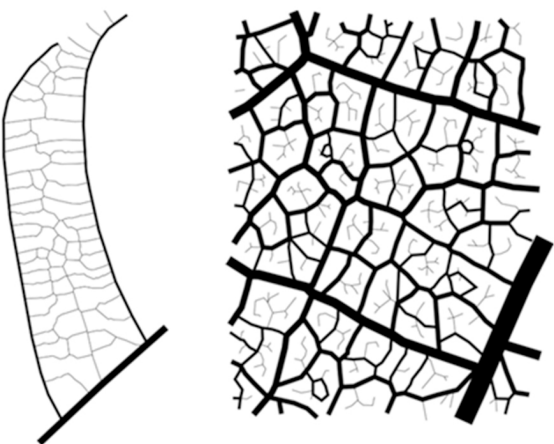

D

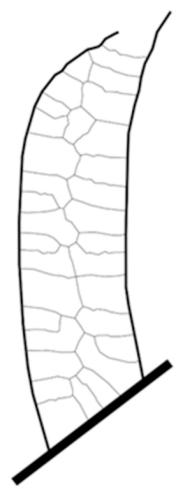

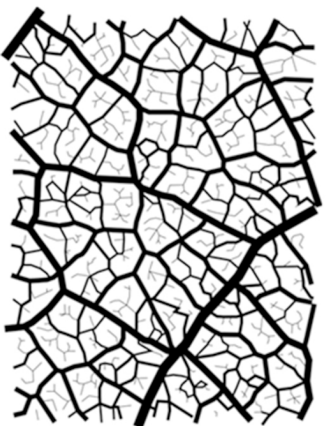

Figura 6. Detalles de venaciones terciarias, areolas y vénulas del limbo medio de foliolos de C. nebulosa. Izquierda: las líneas de mayor a menor grosos representan a la vena primaria, secundarias y terciarias, respectivamente (escala izquierda); derecha: detalles de arolas y vénulas (escala derecha). (A) muestra 'N1'; (B) muestra 'N2'; (C) muestra 'N3'; (D) muestra 'N4'. Escala izquierda $=2 \mathrm{~cm}$; escala derecha $=1000 \mu \mathrm{m}$.

vena primaria, inter-espaciadas irregular o uniformemente, aumentando hacia la base y ápice; ángulo de divergencia de las venas secundarias en el ápice agudo-moderado $\left(65-45^{\circ}\right)$ y agudo-ancho $\left(65-80^{\circ}\right)$, en el limbo medio agudo-moderado y agudo-ancho, y en la base agudo-ancho y recto $\left(80-100^{\circ}\right)$; recorrido en el ápice recto, uniformemente curvo y raramente in zigzag, en el limbo medio abrupta- y uniformemente curvo, y en la base recurvo y abruptamente curvo (Figura 5). Venas inter-secundarias poco frecuentes (25$50 \%$ ), simples y compuestas; ángulo predominantemente de divergencia en relación con la parte apical de la vena primaria en el ápice agudo-ancho, en el limbo medio agudo-an- cho y recto, y en la base agudo-ancho (Figura 5). Venas terciarias con patrón mixto alterna/ opuesta-percurrente, curso bifurcado y sinuoso; ángulo en relación con venas secundarias recto, y en relación con la vena primaria oblicuo, decreciendo apicalmente (Figura 6). Venas cuaternarias con patrón alterna percurrente - reticuladas al azar; ancho débil relativo a la vena terciaria. Venas quintenarias reticuladas al azar. Venas sextenarias reticuladas al azar o dicotomizadas (venas ramifican libremente). Venas septenarias dicotomizadas si es que las sextenarias no son dicotomizadas. Venación final marginal arqueada sin dientes (Figura 5). Areolas bien desarrolladas; pequeñas (0.01-0.1 $\left.\mathrm{mm}^{2}\right)$ a muy pequeñas $\left(<0.01 \mathrm{~mm}^{2}\right)$ escasas $\mathrm{y}$ 
Venación foliar de tres especies de Cedrela (Meliaceae)

\begin{tabular}{|c|c|c|c|c|c|c|c|c|c|c|c|c|}
\hline 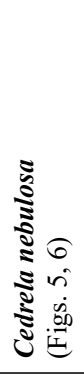 & 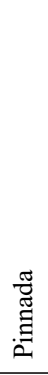 & 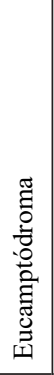 & $\begin{array}{l}\overline{\overline{0}} \\
\overline{0} \\
\overline{0}\end{array}$ & 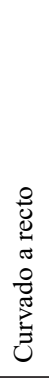 & 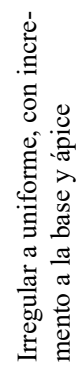 & 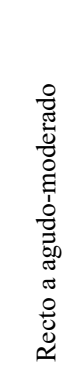 & 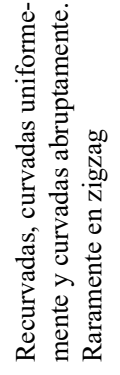 & 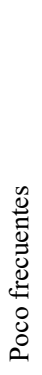 & 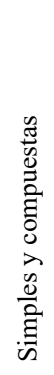 & 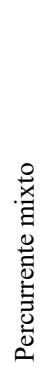 & 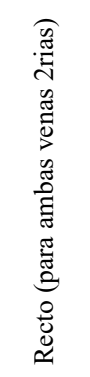 & 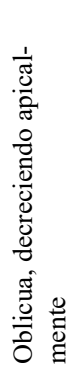 \\
\hline 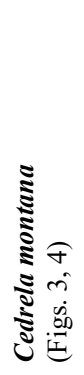 & 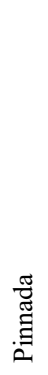 & 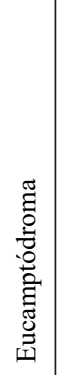 & 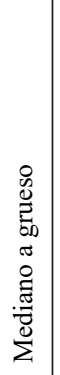 & 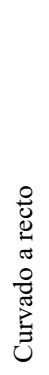 & 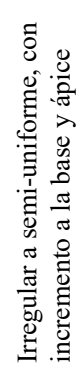 & 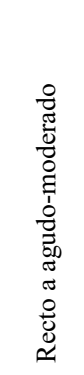 & 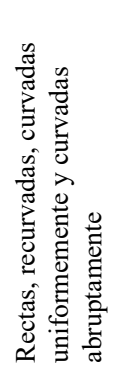 & 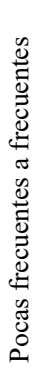 & 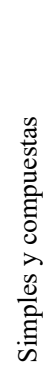 & 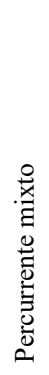 & 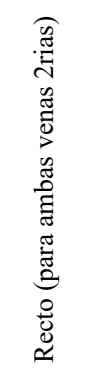 & 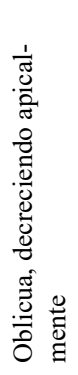 \\
\hline 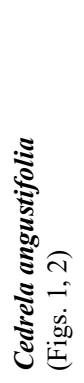 & 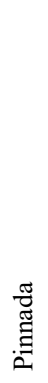 & 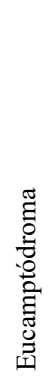 & 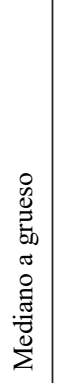 & 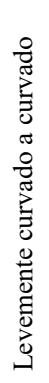 & 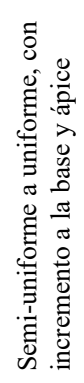 & 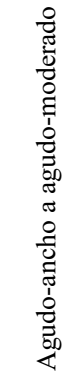 & 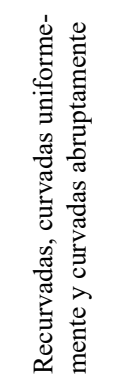 & 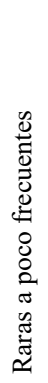 & 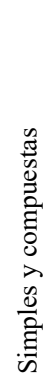 & 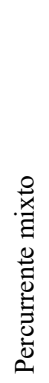 & 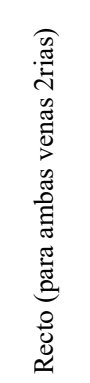 & 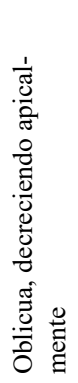 \\
\hline 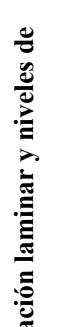 & 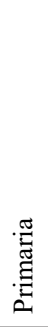 & 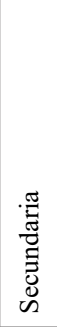 & 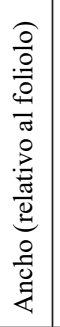 & 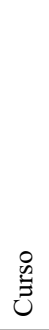 & 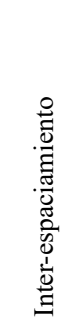 & 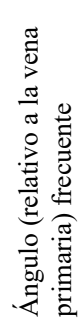 & 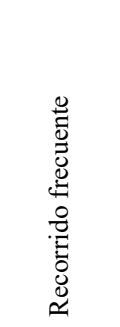 & 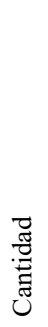 & $\stackrel{\circ}{ٌ}$ & 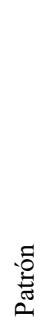 & 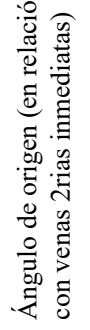 & 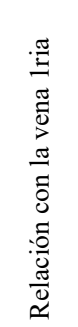 \\
\hline 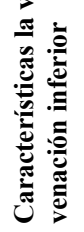 & . & 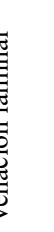 & 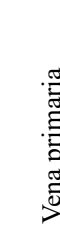 & 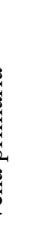 & \multicolumn{3}{|c|}{ 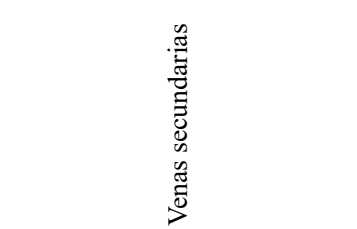 } & \multicolumn{2}{|c|}{ 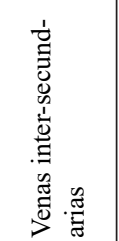 } & \multicolumn{3}{|c|}{ 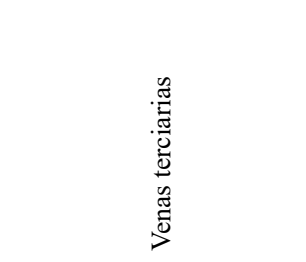 } \\
\hline
\end{tabular}




\begin{tabular}{|l|l|l|l|}
\hline $\begin{array}{l}\text { Características de niveles } \\
\text { de venación inferior }\end{array}$ & $\begin{array}{l}\text { Cedrela angustifolia } \\
\text { (Figs. 1, 2) }\end{array}$ & $\begin{array}{l}\text { Cedrela montana } \\
\text { (Figs. 3, 4) }\end{array}$ & $\begin{array}{l}\text { Cedrela nebulosa } \\
\text { (Figs. 5, 6) }\end{array}$ \\
\hline Curso de venas cuaternarias & Percurrente alterna & $\begin{array}{l}\text { Percurrente alterna o } \\
\text { reticuladas al azar }\end{array}$ & $\begin{array}{l}\text { Percurrente alterna o } \\
\text { reticuladas al azar }\end{array}$ \\
\cline { 2 - 5 } & $\begin{array}{l}\text { Ancho medio relativo a } \\
\text { las venas terciarias }\end{array}$ & $\begin{array}{l}\text { Ancho medio relativo a } \\
\text { las venas terciarias }\end{array}$ & $\begin{array}{l}\text { Ancho tiende a ser débil } \\
\text { relativo a las venas } \\
\text { terciarias (menor a la } \\
\text { mitad del ancho de venas } \\
\text { terciarias) }\end{array}$ \\
\hline Curso de venas quintas & Reticuladas al azar & Reticuladas al azar & Reticuladas al azar \\
\hline Curso de venas sextenarias & Reticuladas al azar & Reticuladas al azar & $\begin{array}{l}\text { Dicomotomizadas o } \\
\text { reticuladas al azar }\end{array}$ \\
\hline Curso de venas septenarias & Dicotomizadas & Dicotomizadas & $\begin{array}{l}\text { Dicotomizadas (si es que } \\
\text { las sextenarias no lo son) }\end{array}$ \\
\hline Venación final marginal & Arqueada sin dientes & Arqueada sin dientes & Arqueada sin dientes \\
\hline
\end{tabular}

Cuadro 3. Resumen de las características de los niveles de venación superior de las tres especies estudiadas.

\begin{tabular}{|l|l|l|l|l|}
\hline \multicolumn{2}{|l|}{$\begin{array}{l}\text { Características de areolas } \\
\text { y vénulas }\end{array}$} & $\begin{array}{l}\text { Cedrela angustifolia } \\
\text { (Fig. 3) }\end{array}$ & $\begin{array}{l}\text { Cedrela montana } \\
\text { (Fig. 6) }\end{array}$ & $\begin{array}{l}\text { Cedrela nebulosa } \\
\text { (Fig. 9) }\end{array}$ \\
\hline Areolación & & Bien desarrolladas & Bien desarrolladas & Bien desarrolladas \\
\hline \multirow{2}{*}{ Areolas } & Tamaño & $\begin{array}{l}\text { Pequeñas predominantes, } \\
\text { muy pequeñas escasas y } \\
\text { medianas raras }\end{array}$ & $\begin{array}{l}\text { Pequeñas predominantes } \\
\text { y muy pequeñas escasas }\end{array}$ & $\begin{array}{l}\text { Pequeñas predominantes, } \\
\text { muy pequeñas escasas y } \\
\text { medianas raras }\end{array}$ \\
\cline { 2 - 5 } & Forma & $\begin{array}{l}\text { Formas variadas, pre- } \\
\text { dominan las de cinco } \\
\text { lados o más }\end{array}$ & $\begin{array}{l}\text { Formas variadas, pre- } \\
\text { dominan las de cinco } \\
\text { lados o más }\end{array}$ & $\begin{array}{l}\text { Formas variadas, pre- } \\
\text { dominan las de cinco } \\
\text { lados o más }\end{array}$ \\
\hline \multirow{2}{*}{ Vénulas } & Presencia & Raramente no presentes & Raramente no presentes & $\begin{array}{l}\text { Rara a pocas veces no } \\
\text { presentes }\end{array}$ \\
\cline { 2 - 5 } & Tipo & $\begin{array}{l}\text { Simples lineales, simples } \\
\text { curvadas, bifurcadas una } \\
\text { vez comunes, bifurcadas } \\
\text { dos veces o más veces } \\
\text { raras }\end{array}$ & $\begin{array}{l}\text { Simples lineales, simples } \\
\text { curvadas, bifurcadas una } \\
\text { vez comunes, bifurcadas } \\
\text { dos veces menos co- } \\
\text { munes, bifurcadas tres o } \\
\text { más veces raras }\end{array}$ & $\begin{array}{l}\text { Simples lineales, simples } \\
\text { curvadas, bifurcadas una } \\
\text { vez comunes, bifurcadas } \\
\text { dos veces o más veces } \\
\text { raras }\end{array}$ \\
\hline
\end{tabular}

Cuadro 4. Resumen de las características de las vénulas y areolas de las tres especies estudiadas. 
medianas $\left(0.1-1 \mathrm{~mm}^{2}\right)$; de cinco lados o más a cuadriláteras y triangulares (Figura 6). Vénulas raramente no presentes; simples lineales a simples curvadas, bifurcadas una vez comunes y bifurcadas dos o más veces (Figura 6).

\section{Venación laminar y niveles de venación infe- rior}

La venación laminar y niveles de venación inferior son muy similares dentro de las especies estudiadas (Cuadro 2). La única de estas características que podría ser usada para la diferenciación de las especies es el ancho de la vena primaria en relación con la lámina foliar, la cual varió entre las especies estudiadas (ANOVA, $\mathrm{F}_{2,9}=5.88, P=0.023^{*}$ ), siendo débil en $C$. nebulosa y moderado a grueso en C. angustifolia y C. montana, y agrupadas respectivamente por la prueba Tukey $(\mathrm{df}=9, P$ $<0.05)$.

\section{Niveles de venación superior}

Los niveles de venación superior son similares dentro de las especies estudiadas (Cuadro 3). La única característica que podría ser usada para la diferenciación de las especies es el ancho de las venas cuaternarias en relación con las venas terciarias, siendo débil en $C$. nebulosa y medio en C. angustifolia y C. montana.

\section{Areolas y vénulas}

Las areolas y vénulas son similares dentro de las especies estudiadas, por lo que no se podrían usar como componentes para su diferenciación (Cuadro 4).

\section{Análisis de correspondencia múltiple}

\section{a) Venas secundarias}

Los resultados del primer MCA (Figura 7A) sugiere que las venas secundarias de C. angustifolia son en general más agudas, mientras las de C. nebulosa y C. montana más obtusas. Se puede distinguir que $C$. angustifolia y $C$. montana poseen una mayor asociación por agudo-anchos, mientras que C. nebulosa por agudo-moderados. Sin embargo, las características medidas de las venas secundarias no ofrecen una clara diferenciación de las especies estudiadas.

\section{b) Venas inter-secundarias}

El segundo MCA (Figura 7B) sugiere que las venas inter-secundarias de C. nebulosa son más agudas, las de $C$. montana son rectas y las $C$. angustifolia se encuentran entre agudos-anchas y obtusas (Figura 7B). Sin embargo, las características medidas de venas inter-secundarias no ofrecen una clara diferenciación de las especies estudiadas.

\section{c) Areolas}

El tercer MCA (Figura 8A) muestra que las areolas de cinco o más lados son comunes para las tres especies estudiadas, mientras que areolas de forma cuadrilátera solo para C. montana y C. nebulosa. En las tres especies estudiadas, las areolas de tamaño muy pequeño y mediano, $y$ de forma triangular son raras. Las características estudiadas de areolas de las tres especies estudiadas no ofrecen una clara diferenciación de las especies estudiadas.

\section{d) Vénulas}

El último MCA (Figura $8 \mathrm{~B}$ ) muestra que particularmente el tipo de vénulas más comunes para C. angustifolia fue simple rectas, para $C$. montana simples rectas, simples curvas y bifurcadas una vez, y finalmente para C. nebulosa simples rectas, simples curvas, bifurcadas una vez y bifurcadas dos veces. Para las tres especies estudiadas, vénulas bifurcadas tres veces o más veces son raras. Las características estudiadas de vénulas no ofrecen una clara diferenciación de las especies estudiadas.

\section{Discusión}

Los resultados muestran que la venación foliar de C. angustifolia, C. montana y C. nebulosa es muy similar, sugiriendo una considerable homogeneidad a nivel género, algo que ha sido observado en otros géneros de Meliaceae (Sarma et al. 1992, Tadavi y Bhadane 2013).

Sin embargo, existen características de la venación foliar que ayudar a diferenciar C. nebulosa de C. angustifolia y C. montana; el ancho de la vena primaria en relación con la lámina foliar y el ancho de las venas cuaternarias en 

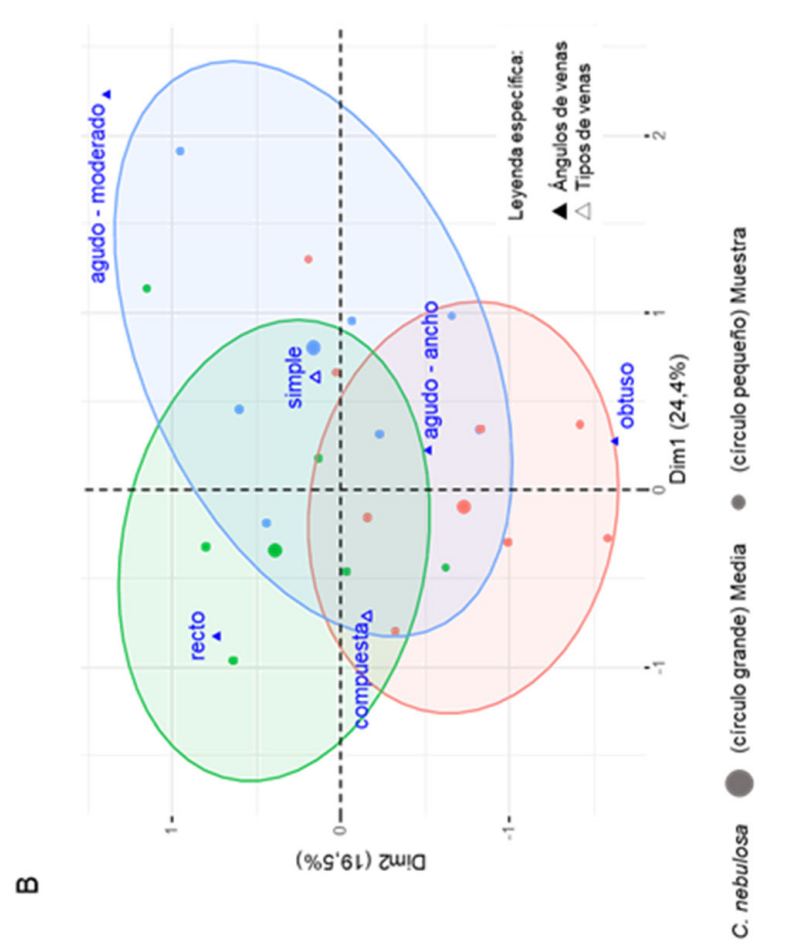

芯 官密

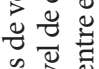

ชี. ए

焉

过

สู้

을

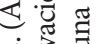

ㄹ.

ช 0

ช สิ क

च :

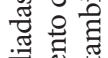

巻

\&

:

की ए

\& छ क

는

สิ జ :

च 己े

สี 크

휼 웝

芯氙 융

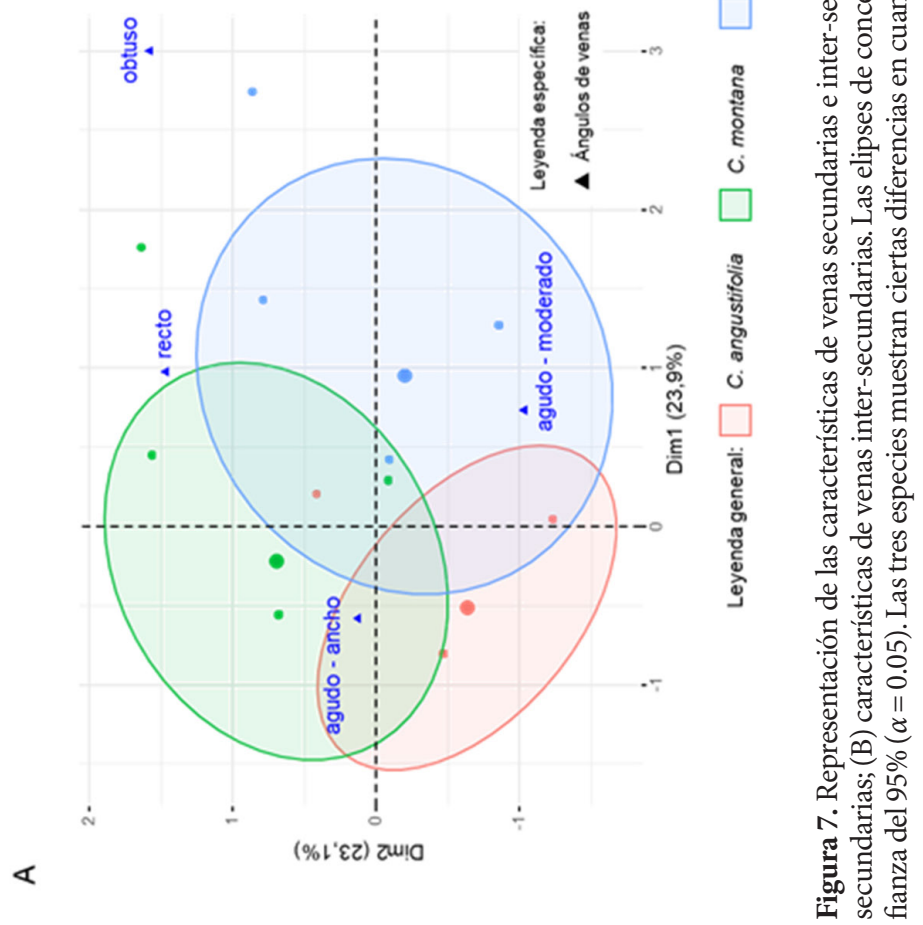


Venación foliar de tres especies de Cedrela (Meliaceae)

๓

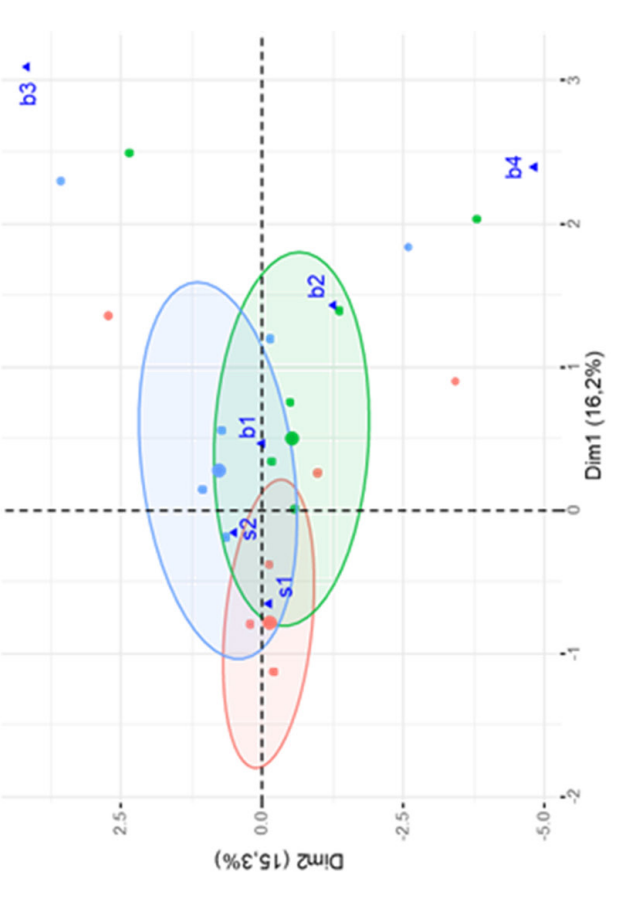

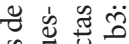

चु $\vec{\Xi} \circlearrowright$

के

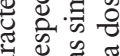

청 ส

(ิ)

要运

웡 엉

항 융 is

षैं.

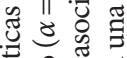

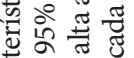

可要

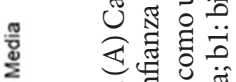

ธूँ ठี

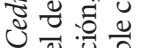

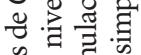

芩获

ซี ซี ซึ

\% $\quad$ है

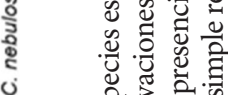

- के

के $\overrightarrow{0}$

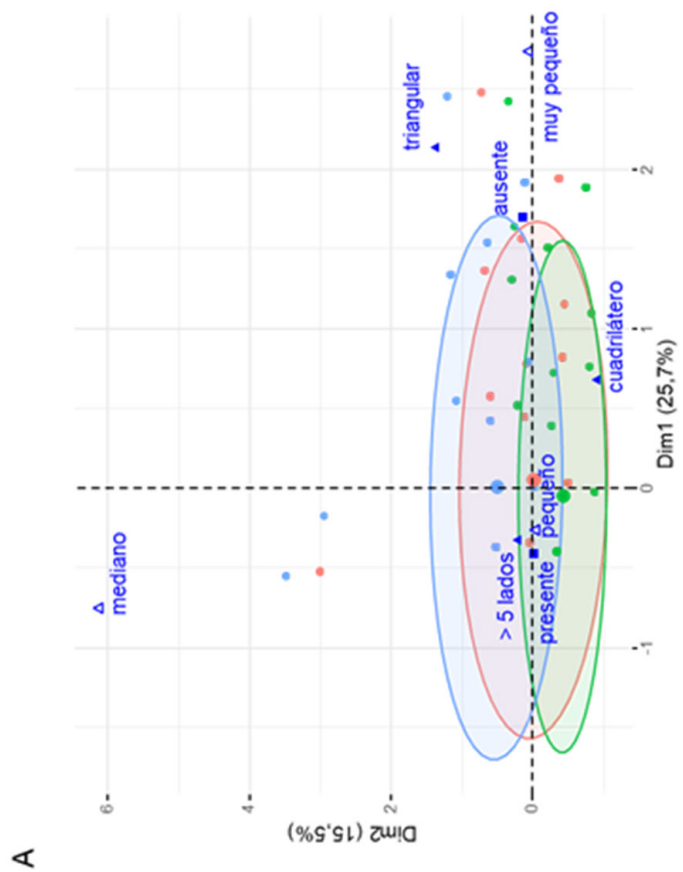

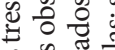

जิ जิ ज़

च च

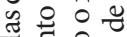

预.

公电

जै

चे 己

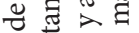

वै चี

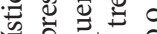

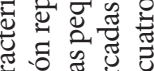

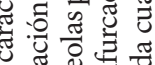

马

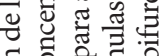

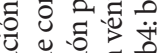

क्ष

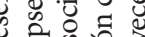

출 웡

थิ ज्ञ

$\infty$ ज

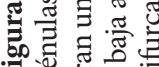


relación con las venas terciarias. La primera característica es usada por Tadavi y Bhadane (2013) para diferenciar dos especies congenéricas de Meliaceae, Melia azedarach L. y Melia dubia Cav., sugiriendo que esta característica podría ser variable a nivel de género. En el caso de las especies estudiadas, esta característica podría ser usada para diferenciar C. nebulosa de $C$. angustifolia y C. montana con ayuda de una regla milimetrada o con un pie de rey, en adición con las características destacadas por Reynel et al. (2017), como pubescencia, forma del foliolo y ancho del foliolo.

La venación laminar es uno de los pocos caracteres de la venación foliar que ha sido descrita para el género Cedrela. La venación foliar de las tres especies estudiadas de Cedrela se encuentra dentro de los rangos descritos por Sarma et al. (1992) y Tadavi y Bhadane (2013) para Meliaceae en general. Nuestro estudio describe a las tres especies estudiadas como eucamptódromas, similar a los resultados de Pennington (2006) a nivel de género, y a los de Pennington y Muellner (2010) nivel de especie. Sin embargo, Pennington y Muellner (2010) describieron a C. montana también como broquidódroma. Esta discrepancia se puede deber a la variabilidad del crecimiento meristemático, como es presumido por Pole (1991), la cual depende de varios factores como la temperatura, luz y nutrimentos del suelo (Chen y Chien 2012). No obstante, no existe información sobre el desarrollo morfológico-foliar de Cedrela para complementar esta hipótesis.

Así mismo, es importante notar que especies de Toona, el género hermano de Cedrela (Cole 2018), muestran una venación laminar únicamente broquidódroma (Sarma et al. 1992, Tadavi y Bhadane 2013), mientras que solo miembros de la subfamilia Melioideae, específicamente algunos Melia spp., muestran una venación laminar craspedódroma (Tadavi y Bhadane 2013). Esto sugiere que dentro de la familia Meliaceae, los caracteres de venación foliar poseen un grado de heterogeneidad y destaca la importancia taxonómica de esta, particularmente de la venación laminar.
Este es el primer estudio donde se describen las venaciones de nivel superior, areolas y vénulas de Cedrela. Los resultados de este estudio revelaron que los niveles de venación de Cedrela pueden llegar hasta el séptimo nivel, coincidiendo con los rangos descrito por Sarma et al. (1992) y Tadavi y Bhadane (2013) para Meliaceae. Sack y Scoffoni (2013) presumen que un alto nivel de jerarquía de venas, tal y como se observó para las tres especies estudiadas de Cedrela, provee de varias ventajas a los foliolos, tales como el incremento de contacto entre tejidos vasculares y fotosintéticos; lo que podría significar una ventaja en su hábitat (Clark y Bullock 2007).

\section{Conclusiones}

Esta investigación es el primer estudio sobre la venación foliar de Cedrela en Perú, donde esta es descrita para C. angustifolia, C. montana y C. nebulosa. Estas tres especies estudiadas presentan una venación foliar similar. El alto grado de homogeneidad de la venación foliar de las especies estudiadas y su heterogeneidad intraespecífica, complica la diferenciación de estas especies usando tan solo caracteres de venación foliar en campo. De las características de venación foliar para diferenciar C. nebulosa, la proporción del ancho de la vena primaria es la más adecuada para la diferenciación de C. angustifolia y C. montana. Sin embargo, se recomienda que la característica se use fuera de la etapa de campo ya que se debería de usar con ayuda de una regla milimetrada o con un pie de rey.

\section{Agradecimientos}

Esta investigación fue financiada por Cienciactiva, CONCYTEC, como parte del proyecto DINAFOR "Dinámica Forestal de los Bosques de la Selva Central del Perú y su adecuación ante el Cambio Climático". Los autores agradecen al Dr. José Luis Marcelo Peña, Mg. Sc. Manuel Chavesta y Mg. Sc. Sonia Palacios Ramos por su orientación y comentarios, los cuales indudablemente mejoraron este artículo. Igualmente, al Herbario Forestal MOL, Laboratorio 
Venación foliar de tres especies de Cedrela (Meliaceae)

de Pulpa y Papel y al Laboratorio de Anatomía de la Madera de la Facultad de Ciencias Forestales de la UNALM por ofrecernos las facilidades para la parte experimental y fotomicrográfica, respectivamente.

\section{Referencias}

Adeyemi, TO; Ogundipe, OT; Olowokudejo, JD. 2013. A review of the taxonomy of African Sapindaceae based on quantitative and qualitative characters. Ife Journal of Science 15(2):303-314.

Andrés-Hernández, AR; Terrazas, T. 2009. Leaf architecture of Rhus s. str. (Anacardiaceae). Feddes Repertorium 120(5-6):293-306. DOI: https://doi.org/10.1002/fedr.200911109.

Ash, A; Ellis, B; Hickey, LJ; Johnson, K; Wilf, P; Wing, S. 1999. Manual of leaf architecture. Washington DC, Estados Unidos de América, Smithsonian Institution. 65 p. DOI: https://doi. org/10.13140/2.1.3674.5282.

Aworinde, DO; Ogundairo, BO; Erinoso, SM. 2013. Comparative leaf architectural studies of some Vernonia SCHREB(Asteraceae) in Nigeria. Current Botany 4(3):43-47.

Barstow, M. 2018. Cedrela fissilis. The IUCN Red List of Threatened Species 2018: e.T33928A68080477. DOI: https:// doi.org/10.2305/IUCN.UK.2018-1.RLTS. T33928A68080477.en.

BGCI (Botanic Gardens Conservation International, Reino Unido); IUCN (International Union for Conservation of $\mathrm{Na}$ ture, Suiza). 2019. Cedrela tonduzii. The IUCN Red List of Threatened Species 2019: e.T146822318A146826862. DOI: $\underline{\text { https:// }}$ dx.doi.org/10.2305/IUCN.UK.2019-2.RLTS. T146822318A146826862.en.

Buijsen, JRM. 1995. Leaf anatomy of Harpullia, Majidea, and Conchopetalum (Sapindaceae). Blumea: Biodiversity, Evolution and Biogeography of Plants 40(2):345-361.

Cao, L; Wang, Z; Cao, M; Liu, J; Lin, Q; Xia, N. 2014. Leaf venation and its systematic significance in Sapindaceae of China. Plant
Diversity and Resources 36(4):419-432. DOI: $\quad$ https://doi.org/10.7525/j.issn.16735102.2017.04.001.

Cervantes, A; Terrazas, T; Hernández, H. 2009. Foliar architecture and anatomy of Bernardia and other genera of Acalyphoideae (Euphorbiaceae). Brittonia 61(4):375-391.DOI: https:// doi.org/10.1007/s12228-009-9084-x.

Chen, C; Chien, M. 2012. The leaf growth model and influencing factors in Phalaenopsis orchid. African Journal of Agricultural Research 7(28):4045-4055.DOI: https://doi.org/10.5897/ AJAR11.1541.

CITES (Convention on International Trade in Endangered Species of Wild Fauna and Flora, Estados Unidos de América). 2021. Apéndices I, II y III (en línea). Washington, Estados Unidos de América. s.e. Consultado 16 abr. 2021. Disponible en: https://cites.org/esp/app/appendices.php.

Clark, B; Bullock, S. 2007. Shedding light on plant competition: modelling the influence of plant morphology on light capture (and vice versa). Journal of theoretical biology 244(2):208-217.DOI: https://doi.org/10.1016/j. jtbi.2006.07.032.

Cole, TCH. 2018. Meliaceae phylogeny poster. Berlín, Alemania, Freie Universität Berlin.

Cronquist, A. 1944. Studies in the Simaroubaceae-II. The genus Simarouba. Bulletin of the Torrey Botanical Club 71(3):226-234. DOI: https://doi.org/10.2307/2481702.

Fonsêca, LC; Proença, CE; Gonçalves, EG. 2007. Descrição do padrão de venação foliar em Spathicarpa Hook. (Araceae). Acta Botanica Brasilica 21(1):213-221. DOI: https://doi. org/10.1590/S0102-33062007000100020.

Fuentes, ACD; Samain, MS; Martínez Salas, E. 2019a. Cedrela discolor. The IUCN Red List of Threatened Species 2019: e. T153072366A153076500. DOI: https:// doi.org/10.2305/IUCN.UK.2019-3.RLTS. T153072366A153076500.en.

Fuentes, ACD; Samain, MS; Martínez Salas, E. 2019b. Cedrela oaxacensis. The 
IUCN Red List of Threatened Species 2019: e.T30762A153076023. DOI: https:// doi.org/10.2305/IUCN.UK.2019-3.RLTS. T30762A153076023.en.

Fuentes, ACD; Samain, MS; Martínez Salas, E. 2019c. Cedrela salvadorensis. The IUCN Red List of Threatened Species 2019: e. T153073106A153076510. DOI: https:// doi.org/10.2305/IUCN.UK.2019-3.RLTS. T153073106A153076510.en.

Gentry, AH. 1996. A field guide to the families and genera of woody plants of northwest South America (Colombia, Ecuador, Peru): with supplementary notes on herbaceous taxa. Washington DC, Estados Unidos de América, Conservation International. 895 p.

Hickey, LJ. 1973. Classification of the architecture of dicotyledonous leaves. American Journal of Botany 60(1):17-33.

Hua, P; Edmonds, JM. 2008. Toona (Endlicher) M. Roemer. In Wu, ZY; Raven, PH; Hong, DY (eds.). Flora of China. Missouri, Estados Unidos de América, MBG Press. v. 11, p. 112-115.

Kassambara, A; Mundt, F. 2017. Factoextra: extract and visualize the results of multivariate data analyses. R package. Vers. 1.0.5.

Lê, S; Josse, J; Husson, F. 2008. FactoMineR: An $\mathrm{R}$ package for multivariate analysis. Journal of Statistical Software 25(1):1-18.

Llamozas, S. 1998. Cedrela lilloi. The IUCN Red List of Threatened Species 1998:e.T32989A9741887. DOI: https:// doi.org/10.2305/IUCN.UK.1998.RLTS. T32989A9741887.en.

Mark, J; Rivers, MC. 2017. Cedrela odorata. The IUCN Red List of Threatened Species 2017:e.T32292A68080590. DOI:_ https:// doi.org/10.2305/IUCN.UK.2017-3.RLTS. T32292A68080590.en.

Muellner, AN; Pennington, TD; Koecke, AV; Renner, SS. 2010. Biogeography of Cedrela (Meliaceae, Sapindales) in central and South america. American Journal of Botany 97(3):511-518. DOI: https://doi.org/10.3732/ajb.0900229.
Muellner, AN; Samuel, R; Johnson, SA; Cheek, M; Pennington, TD; Chase, MW. 2003. Molecular phylogenetics of Meliaceae (Sapindales) based on nuclear and plastid DNA sequences. American Journal of Botany 90(3):471-480. DOI: https://doi.org/10.3732/ajb.90.3.471.

Muntoreanu, TG; da Silva Cruz, R; Melo-de-Pinna, GF. 2011. Comparative leaf anatomy and morphology of some neotropical $\mathrm{Ru}-$ taceae: Pilocarpus Vahl and related genera. Plant systematics and evolution 296(1):8799. DOI: https://doi.org/10.7525/j.issn.1673$\underline{5102.2017 .04 .001 .}$.

Pacheco-Trejo, J; Terrazas, T; Ochoterena, $\mathrm{H}$. 2009. Leaf architecture of the genus Didymaea Hook. f. (Rubiaceae). Plant Systematics and Evolution 281(1):137-149. DOI: https://doi. org/10.1007/s00606-009-0195-3.

Pariente, ME. 2018. Taxonomía, distribución y estado de conservación de las especies del género Dipteryx (fabaceae) en el Perú. Tesis PhD. Lima, Perú, UNALM. 63 p.

Pennington, TD. 1981. A Monograph of tropical Meliaceae. Bronx, Nueva York, The New York Botanical Garden. 470 p.

Pennington, TD. 2006. Flora da Reserva Ducke, Amazonas, Brasil: Meliaceae. Rodriguesia 57(2):207-246. DOI: https://doi. org/10.1590/2175-7860200657208.

Pennington, TD; Muellner, AN. 2010. A monograph of Cedrela (Meliaceae). Milborne Port, Inglaterra, DH Books. $112 \mathrm{p}$.

Pole, M. 1991. A modified terminology for angiosperm leaf architecture. Journal of the Royal Society of New Zealand 21(4):297-312. DOI: https://doi.org/10.1080/03036758.1991.10420 $\underline{828}$.

R Core Team. 2019. R: a language and environment for statistical computing. Vienna, Austria, $\mathrm{R}$ foundation for statistical computing. $2630 \mathrm{p}$.

Reynel, C; Kometter, R; Chavesta, M; Vargas, C; Palacios, S; Montenegro, R; Daza, A; Huaman, D; Kometter, E; Gutiérrez, PH; Nuñez, NFR. 2017. Evaluación dendrológica y anatómica de las especies del género Cedrela. Lima, Perú, MI- 
NAM. 108 p. Servicio de consultoría ejecutada por BioModus Tropical.

Reynel, C; Pennington, R; Pennington, T; Flores, C; Daza, A. 2003. Arboles útiles de la Amazonia peruana y sus usos. Lima, Perú, Herbario FCFUNALM. 537 p.

Sack, L; Scoffoni, C. 2013. Leaf venation: structure, function, development, evolution, ecology and applications in the past, present and future. New Phytologist 198(4):983-1000. DOI: https://doi.org/10.1111/nph.12253

Samain, MS; Fuentes, ACD; Martínez Salas, E. 2019. Cedrela dugesii. The IUCN Red List of Threatened Species 2019: e. T153072469A153076505. DOI: https:// doi.org/10.2305/IUCN.UK.2019-3.RLTS. T153072469A153076505.en.

Sarma, V; Raja Rao, SS; Beena, CH. 1992. Leaf architecture in relation to taxonomy: Meliaceae. Feddes Repertorium 103(7-8):535-542. DOI: https://doi.org/10.1002/fedr.19921030710.

Schindelin, J; Arganda-Carreras, I; Frise, E; Kaynig, V; Longair, M; Pietzsch, T; Preibisch, S; Rueden, C; Saalfeld, S; Schmid, B; Tinevez, J; White, DJ; Hartenstein, V; Eliceiri, K; Tomancak, P; Cardona, A. 2012. Fiji: an open-source platform for biological-image analysis. Nature methods 9(7):676-682.

Tadavi, SC; Bhadane, VV. 2013. Leaf architectural studies in some Meliaceae. Indian Journal of Pure \& Applied Biosciences 28(2):121-132.

Tejero-Díez, D; Aguilar-Rodríguez, S; Terrazas, T; Pacheco, L. 2010. Arquitectura y anatomía foliar del complejo Polypodium plesiosorum sensu Moran (Polypodiaceae). Revista de Biología Tropical 58(3):955-976.

Wendt, T; Lott, EJ. 1985. A new simple-leaved species of Recchia (Simaroubaceae) from southeastern Mexico. Brittonia 37(2):219-225. DOI: https://doi.org/10.2307/2806115. 